\title{
Amyloid-beta transporter expression at the blood-CSF barrier is age-dependent
}

\author{
Crissey L Pascale", Miles C Miller', Catherine Chiu', Matthew Boylan', Ilias N Caralopoulos', Liliana Gonzalez², \\ Conrad E Johanson ${ }^{1}$ and Gerald D Silverberg ${ }^{1 *}$
}

\begin{abstract}
Background: Age is the major risk factor for many neurodegenerative diseases, including Alzheimer's disease (AD). There is an accumulation of amyloid-beta peptides $(A \beta)$ in both the $A D$ brain and the normal aging brain. Clearance of $A \beta$ from the brain occurs via active transport at the blood-brain barrier (BBB) and blood-cerebrospinal fluid barrier (BCSFB). With increasing age, the expression of the $A \beta$ efflux transporters is decreased and the $A \beta$ influx transporter expression is increased at the $\mathrm{BBB}$, adding to the amyloid burden in the brain. Expression of the $A \beta$ transporters at the choroid plexus (CP) epithelium as a function of aging was the subject of this study.

Methods: This project investigated the changes in expression of the A $\beta$ transporters, the low density lipoprotein receptor-related protein-1 (LRP-1), P-glycoprotein (P-gp), LRP-2 (megalin) and the receptor for advanced glycation end-products (RAGE) at the BCSFB in Brown-Norway/Fischer rats at ages 3, 6, 9, 12, 20, 30 and 36 months, using real time RT-PCR to measure transporter mRNA expression, and immunohistochemistry $(\mathrm{IHC})$ to measure transporter protein in isolated rat CP.

Results: There was an increase in the transcription of the A $\beta$ efflux transporters, LRP-1 and P-gp, no change in RAGE expression and a decrease in LRP-2, the CP epithelium influx transporter, at the BCSFB with aging. Decreased $A \beta 42$ concentration in the $C P$, as measured by quantitative $I H C$, was associated with these $A \beta$ transporter alterations.
\end{abstract}

Conclusions: Age-dependent alterations in the CP A $\beta$ transporters are associated with a decrease in $A \beta 42$ accumulation in the $C P$, and are reciprocal to the changes seen in these transporters at the BBB, suggesting a possible compensatory role for the BCSFB in A $\beta$ clearance in aging.

Keywords: aging, amyloid-beta, transport, choroid plexus, blood-CSF-barrier, LRP-1, LRP -2, P-gp, RAGE

\section{Background}

Advancing age is a major risk factor for many neurodegenerative disorders, and the major risk factor for Alzheimer's disease (AD), a disease characterized by progressive memory and cognitive loss [1]. The most accepted hypothesis for the mechanism of brain injury in $\mathrm{AD}$ is the "amyloid cascade," comprising amyloid accumulation in the brain, the formation of toxic oligomeric and intermediate forms of amyloid-beta peptides $(\mathrm{A} \beta)$, amyloid plaques, inflammation and the induction of neurofibrillary tangles [2-4]. There is accumulation of

\footnotetext{
* Correspondence: geralds@stanford.edu

'Warren Alpert Medical School Brown University, RI Hospital Department of Neurosurgery 593 Eddy St. Providence, RI 02903 USA Full list of author information is available at the end of the article
}

$\mathrm{A} \beta$ in both the normal aging brain and the AD brain, thought to be related to defective $A \beta$ clearance rather than increased $A \beta$ production [4-7]. This has recently been shown to be the case in AD [8]. Clearance of this peptide from the brain occurs via active transport at the interfaces separating the central nervous system from the peripheral circulation.

We have recently shown that the blood-brain barrier (BBB) undergoes significant alterations in $\mathrm{A} \beta$ transporter expression with aging [5,9]. These changes likely lead to a decrease in amyloid efflux from the brain and an increase in amyloid influx, associated with an increasing CNS amyloid burden. Similar A $\beta$ transporter expression changes have been shown in AD brains [10-12]. The blood-CSF barrier (BCSFB) also undergoes
C Biomed Central 
age-related changes, and it is important to study the effects of aging on this alternative pathway for transporter-mediated amyloid clearance $[13,14]$.

$\mathrm{BBB} A \beta$ clearance is an energy-dependent (active) process via specific transporter proteins $[15,16]$. The receptors for $A \beta$ at the $B B B$ bind $A \beta$ directly, or bind to one of its carrier proteins, and transport it across the endothelial cell. The low density lipoprotein receptorrelated protein 1 (LRP-1) and P-glycoprotein (P-gp) have been implicated in $A \beta$ efflux $[17,18]$. LRP- 1 is located on the abluminal endothelial cell membrane, whereas P-gp is located on the luminal (blood-facing) surface. The receptor for advanced glycation end products (RAGE), also located on the luminal side of the endothelium, has been linked to $A \beta$ influx [19].

It has been hypothesized that $\mathrm{AD}$ is on a continuum with normal aging, although the exact causes for the transition from aging to AD are not yet fully understood $[14,20]$. In addition to the reduction in clearance of $A \beta$ across the $\mathrm{BBB}$ with increased age, there is also a decline in its clearance via CSF bulk flow [21]. We have also demonstrated that interfering with the bulk flow of CSF by induced hydrocephalus causes amyloid to accumulate in the aged rat brain [22]. An increase in ventricular size and a decrease in CSF production and turnover have been demonstrated in senescence, AD and hydrocephalus of the elderly $[21,23,24]$. Decreased CSF turnover has been postulated to be an important risk factor for $\mathrm{AD}[7,14]$.

Solute transport at the BCSFB occurs across the choroid plexus (CP) epithelium $[25,26]$. Although CSF bulk flow decreases with age and $\mathrm{AD}$, active transport of solutes, such as $A \beta$, across the $C P$ may not. The same $A \beta$ transporters located on the endothelial cells of the BBB are also found at the BCSFB, e.g., LRP-1, P-gp and RAGE, as well as another receptor known to transport $A \beta$ from the CSF into the $\mathrm{CP}$ epithelium, the low density lipoprotein receptor-related protein 2 (LRP-2). Although the LRP receptors may transport solutes bi-directionally, there is evidence that LRP-1 and P-gp are A $\beta$ efflux transporters and LRP-2 primarily transports $A \beta$ from CSF into the CP epithelium [27-30]. Herein, we report the changes in mRNA expression and receptor protein density of these $A \beta$ transporters on the CP epithelium as a function of age. Expression of receptor mRNA was measured by real time reverse transcription-polymerase chain reaction (RT-PCR). Immunohistochemistry (IHC) was used for protein sub-cellular localization and semi-quantitative measurements of receptor expression. IHC was also used to measure $A \beta 40$ and A 342 accumulation in $\mathrm{CP}$ with advancing age. Interestingly, the overall changes in expression that we found at the BCSFB were reciprocal to those seen at the BBB, and different from $\mathrm{AD} C \mathrm{CP}$.

\section{Methods}

\section{Tissue collection}

All experiments were approved by the Rhode Island Hospital Institutional animal care and use committee. Male Brown-Norway/Fischer $(\mathrm{B}-\mathrm{N} / \mathrm{F})$ rats $(\mathrm{n}=254)$ were purchased from the National Institute on Aging at ages $3,6,9,12,20,30$, and $36 \mathrm{mo}$. B-N/F rats are not as susceptible to cancer as the more inbred species and can live in excess of 36 mo. Under a surgical plane of anesthesia, induced by intraperitoneal injection of pentobarbital $(50 \mathrm{mg} / \mathrm{kg})$, the animals were perfused with $0.9 \mathrm{M}$ phosphate buffered saline (PBS), $\mathrm{pH} 7.4$, at $4^{\circ} \mathrm{C}$ via the left ventricle of the heart, using a peristaltic pump (Harvard Apparatus, Holliston, MA, USA). The two lateral ventricle CPs were then dissected out under a microscope and placed in a microcentrifuge tube containing either $4 \%$ paraformaldehyde (PFA) for fixation prior to IHC, or RNAlater (Ambion, Austin, TX, USA) to limit degradation by endonucleases before RT-PCR analysis. Eight CPs from four rats were pooled for each sample used downstream for PCR, and two CPs from one rat were used for each IHC sample. For PCR, $n=8$ (32 rats) were tested for each age group and for IHC n = 5 (five rats) were used for each age group.

\section{Real time RT-PCR}

Samples stored in RNAlater were allowed to thaw and were rinsed with nuclease-free water before homogenizing in the lysis buffer provided in the Qiagen RNeasy kit (Qiagen, Valencia, CA, USA). This kit was used, per the manufacturer's instructions, to extract the RNA. RNA concentrations were measured by a NanoDrop 1000 spectrophotometer (ThermoFisher Scientific, Wilmington, DE, USA) and stored at $-80^{\circ} \mathrm{C}$ until further use. 1 $\mu \mathrm{g}$ of RNA was used with the Omniscript Reverse Transcription kit (Qiagen) to synthesize $20 \mu \mathrm{L}$ of cDNA. Forward (F) and reverse (R) primers for each gene of interest were designed using Primer Premier software (PREMIER Biosoft International, Palo Alto, CA, USA). The primers used were as follows (written from 5 ' to 3 '): LRP-1 F CAAGATGTATGAAGGTGGAGAGC, LRP-1 R ACTGGGTTGGTGAAGTTGGTAG $\left(\mathrm{T}_{\mathrm{A}}=62^{\circ}\right)$; LRP-2 F GCAGAGATGGACAGTGAGGT, LRP-2 R GCTGG CGAGGCTATACG $\left(\mathrm{T}_{\mathrm{A}}=62^{\circ}\right)$; P-gp F GGACAAAGCCAGGGAAGG, P-gp R GGTGGGTGCCGTGCTC $\left(\mathrm{T}_{\mathrm{A}}=\right.$ $\left.60^{\circ}\right)$; RAGE F GCAGGCTCTGTGGATGGG, RAGE R GAGTCTGGGTTGTCGTTTTCG $\left(\mathrm{T}_{\mathrm{A}}=62^{\circ}\right)$; and $\beta$ ACT F AAAGACCTCTATGCCAACACAGT, $\beta A C T$ R GAGC$C A C C A A T C C A C A C A G\left(\mathrm{~T}_{\mathrm{A}}=60^{\circ}\right)$. In each $50 \mu \mathrm{L}$ real time RT-PCR reaction using SYBR-ER master mix (Invitrogen, Carlsbad, CA, USA), $10 \mathrm{mM}$ primers and $1 \mu \mathrm{L}$ cDNA were implemented. Reactions were run in a BioRad iCycler (Bio-Rad, Hercules, CA, USA) using 
Invitrogen's suggested protocol. Annealing temperatures $\left(\mathrm{T}_{\mathrm{A}}\right)$ varied and were specific for each primer set. Standards corresponding to each gene were generated by first amplifying template DNA ( $\beta$ ACT: rat cerebral cortex; LRP-1 and RAGE: rat lung; LRP-2: rat kidney; P-gp: rat liver) using a set of gene-specific primers in eight $100 \mu \mathrm{L}$ RT-PCR reactions. An equal volume of phenol: chloroform was then added to the combined product and mixed vigorously for $15 \mathrm{sec}$. After sitting on ice for $10 \mathrm{~min}$, the mixture was centrifuged for $20 \mathrm{~min}$ on maximum speed at $4^{\circ} \mathrm{C}$. The aqueous phase was carefully removed to another microcentrifuge tube where $1 / 10$ volume of sodium acetate was added and mixed. An equal volume of $100 \%$ ice cold ethanol was added and allowed to sit overnight in a $-20^{\circ} \mathrm{C}$ freezer. The DNA was pelleted, resuspended in $20 \mu \mathrm{L}$ Tris EDTA buffer, and run on a $2.5 \%$ low melting temperature agarose gel (Fisher Scientific, Fairlawn, NJ, USA) in Tris Borate EDTA buffer for $1.5 \mathrm{~h}$. Due to the intercalating dye, Gelred (Biotium, Hayward, CA, USA), that was added to the gel pre-run, the DNA band was visualized under UV light and was then extracted. The DNA was purified from each gel slice using Promega Wizard columns (Promega, Madison, WI, USA). The concentration of DNA was determined using a spectrophotometer (ThermoFisher Scientific) and a serial dilution for each gene of interest was created $\left(10^{2}\right.$ to $10^{6}$ copies per $\left.\mu \mathrm{L}\right)$. Standards for a particular gene were run in each reaction corresponding to that gene. Both standards and samples were run in duplicate, and all runs contained an interrun calibrator to account for any differences between runs. A melt curve was generated for every reaction and viewed to ensure only the gene of interest was being amplified. All data were normalized to the housekeeping gene, $\beta$-actin $(\beta \mathrm{ACT})$, before statistical analysis was performed.

\section{Immunohistochemistry}

Specimens stored in PFA were processed, embedded in paraffin, and sectioned at a thickness of $10 \mu \mathrm{m}$. After deparaffinization and rehydration, tissue sections were treated with hot $\left(85^{\circ} \mathrm{C}\right) 10 \mathrm{mM}$ citrate buffer, $\mathrm{pH} 6$, for $20 \mathrm{~min}$. Sections were washed with distilled water and quenched with a peroxidase-blocking reagent (Dako, Carpinteria, CA, USA) for $10 \mathrm{~min}$ at room temperature to eliminate endogenous peroxidase activity. After washing in $0.05 \mathrm{M}$ Tris-buffered saline with $0.05 \%$ Tween-20 (TBST), pH 7.6, sections were incubated overnight at $4^{\circ}$ $\mathrm{C}$ with their appropriate primary antibody: rabbit polyclonal to A $\beta 40$ (Linaris, Wertheim-Bettingen, Germany; Cat. \# PAK6012, diluted 1:100), rabbit polyclonal to A 42 (Linaris, \# PAK6023, diluted 1:200), rabbit polyclonal to LRP-1 (Orbigen, San Diego, CA, USA; \# PAB10774 , diluted $1: 1000)$, rabbit polyclonal to LRP-2
(Orbigen, \# PAB-10775, diluted 1:2000), mouse monoclonal to P-glycoprotein (Abcam, Cambridge, MA, USA; \# ab3364, diluted 1:100), or goat polyclonal to RAGE (Abcam, \# ab7764, diluted 1:400). After washing the sections in TBST, a horseradish peroxidase (HRP)-labeled polymer conjugated with secondary antibodies: antimouse (Dako) or anti-rabbit (Dako), was applied for 30 min at room temperature, in accordance with the EnVision+ System for IHC staining. For RAGE only, the sections were instead subjected to a modified $A B C$ technique using the Vectastain Elite ABC Goat Peroxidase system (Vector Laboratories, Burlingame, CA, USA). All tissue sections were washed in TBST and stained using 3,3-diaminobenzidine (Dako) as the chromogen. Following development, P-gp sections were counterstained for $30 \mathrm{sec}$ with a $1 \%$ light green SF yellowish solution (Sigma, St. Louis, MO, USA). Sections were dehydrated through a series of graded alcohols and xylene, and then coverslipped and sealed using Cytoseal XYL, a xylene-based mounting medium (Richard-Allan Scientific, Kalamazoo, MI, USA). Primary antibody omission controls were run alongside the other samples to check for non-specific binding due to the secondary antibody, along with positive control tissue (human hippocampus with Braak and Braak Stage VI AD pathology, human lung, and human kidney).

\section{Image Analysis}

All IHC slides were converted to digital images using Aperio ScanScope (Aperio Technologies, Vista, CA, USA) as 8-bit acquisitions of color. Image analysis was completed in Image J (v. $1.43 \mathrm{u}, \mathrm{NIH}$, Bethesda, MD, USA). For all stains except for P-gp, stained tissue was selected on the Red Channel based on a specific threshold value, and the 'Mean Gray Value' was measured from the selection. This value renders the average stain intensity as grayscale units (GU) for all thresholded pixels. Quantification of P-gp immunoreactivity was determined by the pixel ratio of stained tissue area to total tissue area [\% region of interest (ROI)]. IHC images were taken for six age groups: $3,6,12,20,30$, and 36 mo. Our semi-quantitative IHC methods have been shown to correlate very closely with western blot measurements of $\mathrm{A} \beta$ receptor protein at the $\mathrm{BBB}[5,9]$.

\section{Statistical methods}

For the RT-PCR analysis, Bio-Rad iQ5 Optical System software (Bio-Rad, Hercules, CA, USA) using the $\Delta \Delta C_{T}$ method to calculate the normalized expression of each gene for each sample was employed. Natural logarithm transformations of the data were used to correct for non-normality and inequality of variances, which was then confirmed by Shapiro-Wilk's and Levene's tests. For both the RT-PCR and the IHC analyses a single- 
factor ANOVA followed by Tukey's pairwise comparisons were used to analyze the data. The confidence limits (CL) for differences in the means (pairwise comparisons) were calculated for the mean of higher mean of lower age group. All statistical analyses were conducted using the SAS software (V. 9.2, SAS Institute, Cary, NC, USA).

\section{Results}

\section{LRP-1}

The expression of the $A \beta$ efflux transporter LRP- 1 at the messenger RNA (mRNA) level as a function of aging was measured by real time quantitative RT-PCR at $3,6,9,12,20,30$, and 36 mo. There was a mild decrease in LRP-1 expression from 3 to 9 mo, followed by a significant increase to $30 \mathrm{mo}$ and then a mild decrease again to 36 mo (Figure 1A). A one-way ANOVA showed an effect of age for the seven tested age groups at the $p<0.05$ level $[\mathrm{F}(6,49)=2.33, p=$ 0.047]. Tukey's pairwise comparisons revealed a significant difference in the mean natural log-transformed normalized expression of LRP-1 between 9 and 30 mo [difference between means $(\mathrm{DMB})=0.5975$; 95\% confidence limits (CL) $(0.0122,1.1828)]$. However, the 3, $6,12,20$, and 36 mo groups did not significantly differ from each other, or from the 9 and 30 mo groups. From 3 to 36 mo, therefore, CP LRP-1 expression was either stable or increased with age.

Semi-quantitative image analysis of the IHC for the LRP-1 protein receptor revealed a similar expression change with aging (Figure 1B). The mean staining intensity was measured in grayscale units (GU). LRP-1 expression was different at the $p<0.05$ level for the six different age groups $[\mathrm{F}(5,24)=5.27, p=0.0021]$. Tukey's pairwise comparison showed a significant increase in mean staining intensity (GU) between 3 and 20 mo $[\mathrm{DBM}=8.633 ; 95 \% \mathrm{CL}(2.052,15.215)]$ and 3 and 30 mo $[\mathrm{DBM}=8.105 ; 95 \% \mathrm{CL}(1.524,14.687)]$. There was a significant decrease from 20 to $36 \mathrm{mo},[\mathrm{DBM}=$ -6.707, 95\% CL (-13.288, -0.125)]. LRP-1 staining

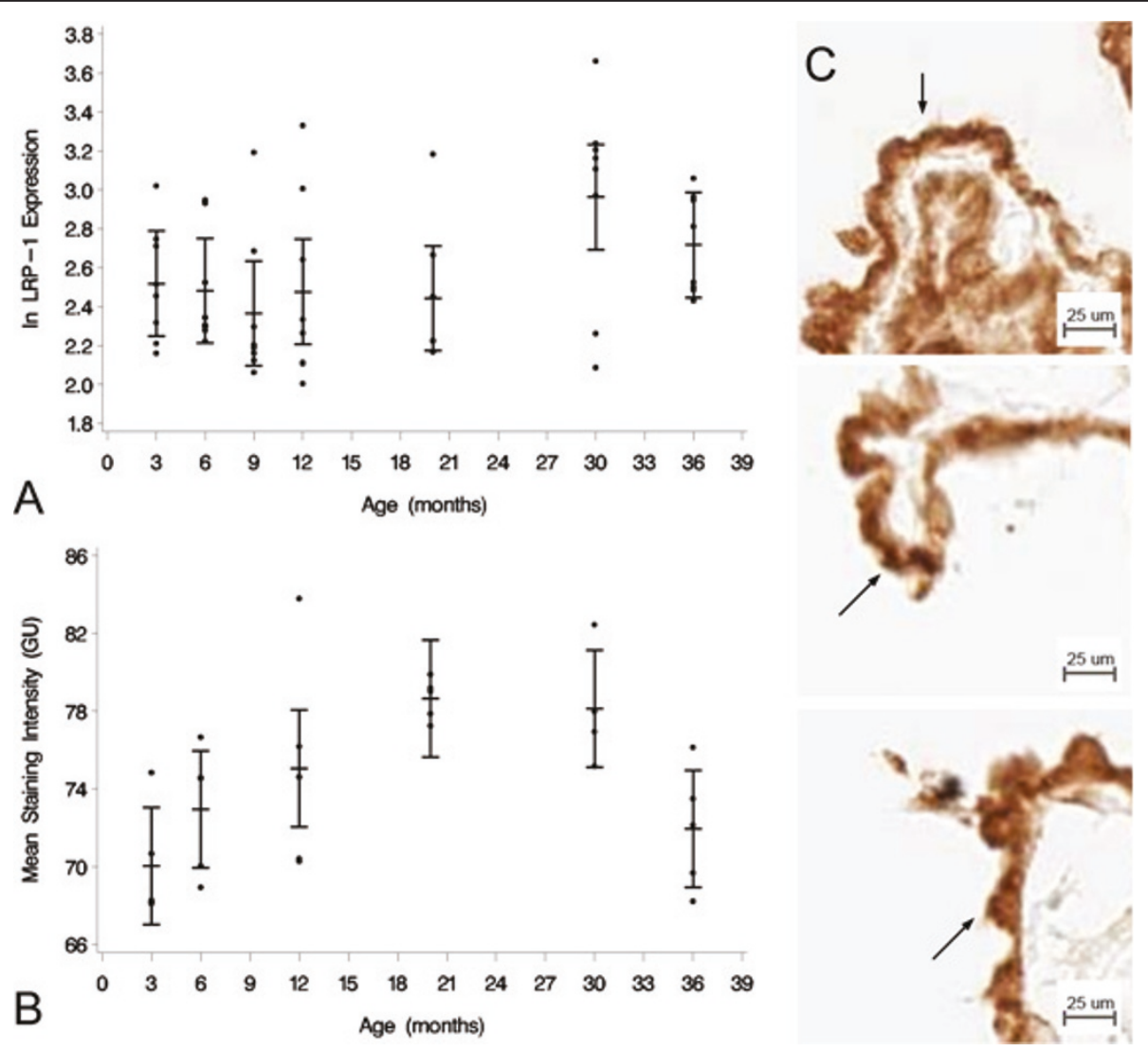

Figure 1 LRP-1 expression at the CP epithelium with age. (A) Graph of the log-transformed normalized expression of LRP-1 with age, $n=8$ for each age group tested ( 4 rats, 8 CPs pooled for each " $n$ ", 32 rats for an $n=8$ ). One-way ANOVA revealed a significant increase in LRP-1 expression $(p=0.047)$. Significance was reached between 9 and 30 mo 95\% confidence limits $(0.0122$, 1.1828). Error bars represent $95 \%$ confidence intervals for the means. (B) Semi-quantitative IHC for LRP-1 expression in grayscale units (GU). Mean staining intensity was significantly different $(p<0.05)$ for the six age groups, $n=5$ for each age group ( 5 rats, 2 CPs for each sample). (C) IHC of LRP-1 expression at 3 mo (top), 30 mo (center) and 36 mo (bottom) old rats. Staining is localized to the apical membrane (arrows). 
appeared to be most intense along the apical membrane of the CP epithelial cell (Figure 1C).

\section{LRP-2}

The expression of the A $\beta$ CP influx transporter LRP-2 at the mRNA level with age was also measured by RTPCR at the same time points as LRP-1. There was a decrease in LRP-2 expression from 3 to 36 mo (Figure 2A). One-way ANOVA showed an effect of age for the seven age groups at the $p<0.05$ level $[\mathrm{F}(6,49)=4.93, p$ $=0.0005]$. Tukey's pairwise comparisons revealed significant differences in the mean natural log-transformed normalized expression of LRP-2 between 3 and 9 mo $[\mathrm{DBM}=0.4323 ; 95 \% \mathrm{CL}(-0.8340,-0.0305)], 3$ and 12 mo $[D B M=0.5061 ; 95 \%$ CL $(-0.9078,-0.1044)], 3$ and 20 mo $[\mathrm{DBM}=0.6270 ; 95 \%$ CL $(-1.0287,-0.2253)], 3$ and $30 \mathrm{mo}[\mathrm{DBM}=0.5183 ; 95 \% \mathrm{CL}(-0.9201,-0.1166)]$ and 3 and $36 \mathrm{mo}[\mathrm{DBM}=0.4887$; 95\% CL $(-0.8904,-$ $0.0869)]$. The results show a continuous decrease in the expression of LRP-2 at the CP epithelium after 3 mo of age.

Semi-quantitative image analysis of the IHC for the LRP-2 protein receptor showed similar results (Figure
2B). The mean staining intensity was different at the $p<$ 0.05 level for the different age groups $[\mathrm{F}(5,24)=3.47, p$ $=0.0168]$. Tukey's pairwise comparison showed a significant decrease in mean staining intensity between 12 and 36 mo [DBM $=-7.924 ; 95 \%$ CL $(-14.199,-1.729)]$. There also appeared to be some localization of the LRP2 staining to the apical membrane of the $\mathrm{CP}$ epithelium, but subapical staining was also evident (Figure 2C).

\section{P-gp}

The expression of $\mathrm{P}$-gp as a function of age, measured by RT-PCR, showed an increase from 3 to 36 mo (Figure 3A). A one-way ANOVA showed an effect of age for the seven age groups at the $p<0.05$ level $[\mathrm{F}(6,49)=$ 4.90, $p=0.0005$ ]. Tukey's pairwise comparisons indicated a significant increase in the mean natural logtransformed normalized expression between 3 and 30 mo $[\mathrm{DBM}=0.5759 ; 95 \% \mathrm{CL}(0.0603,1.0915)], 6$ and 30 mo $[\mathrm{DBM}=0.7134 ; 95 \% \mathrm{CL}(0.1978,1.2290)], 9$ and 30 months $[\mathrm{DBM}=0.5454 ; 95 \% \mathrm{CL}(0.0298,1.0610)], 12$ and $30 \mathrm{mo}[\mathrm{DBM}=0.6153 ; 95 \% \mathrm{CL}(0.0997,1.1309)]$, and between 6 and 36 mo [DBM $=0.5620 ; 95 \% \mathrm{CL}$ $(0.0464,1.0776)]$. These results indicate that P-gp

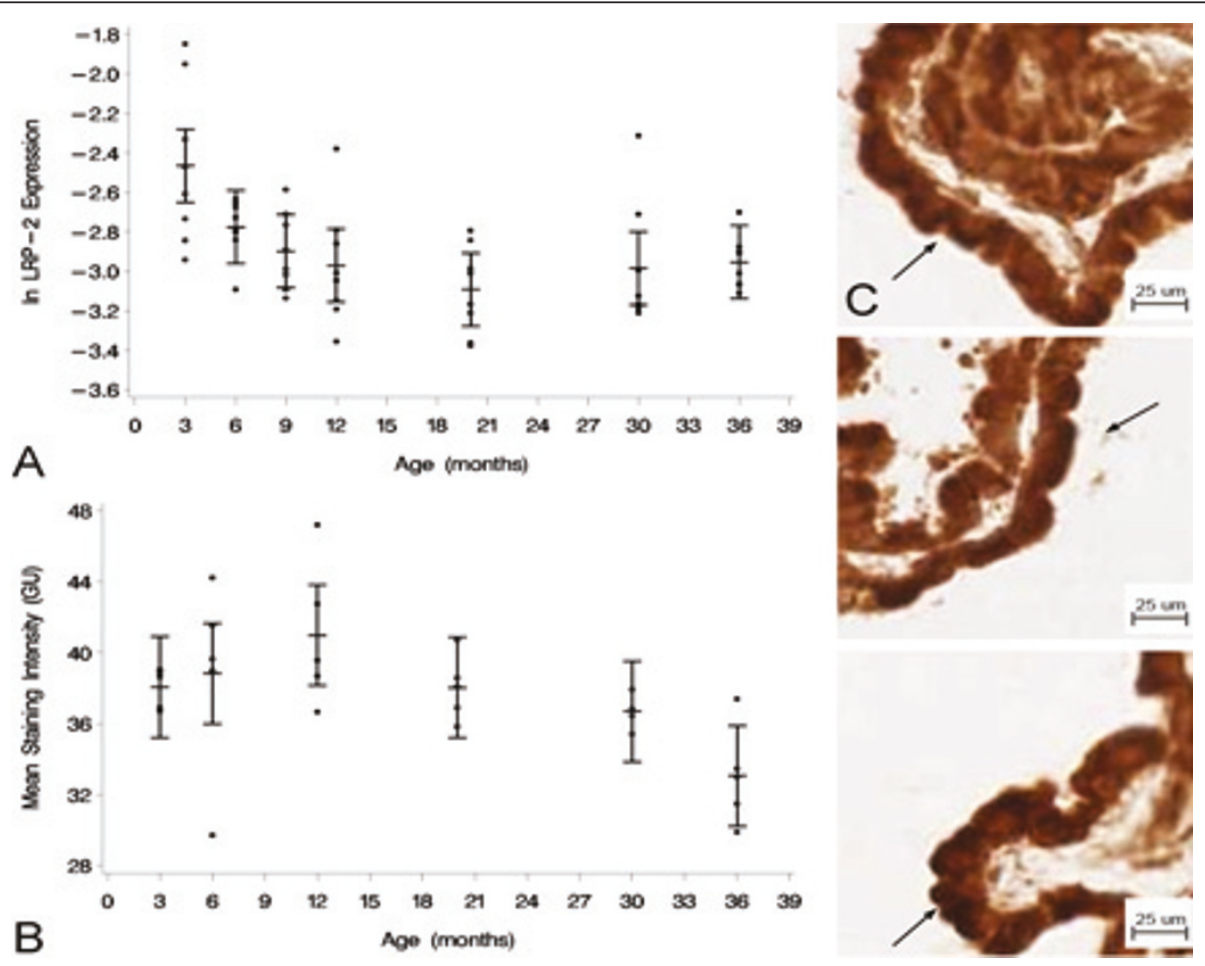

Figure 2 Expression of LRP-2 at the CP with age. (A) Graph of the log-transformed normalized expression of LRP-2 with respect to age, $\mathrm{n}=8$ per age group. One-way ANOVA revealed a significant decrease $(p=0.0005)$ with age on LRP-2 expression. Significance was reached between 3 and 9, 12, 20, 30, and 36 mo. Error bars represent 95\% confidence intervals for the means. (B) Semi-quantitative IHC for LRP-2 expression in grayscale units (GU). Mean staining intensity was significantly decreased $(p<0.05)$ for the age groups, $n=5$ per age group. (C) IHC of LRP-2 expression at $3 \mathrm{mo}$ (top), $20 \mathrm{mo}$ (center), and $36 \mathrm{mo}$ (bottom) old rats. Staining is localized to the apical membrane (arrows), and is also seen subapically. 


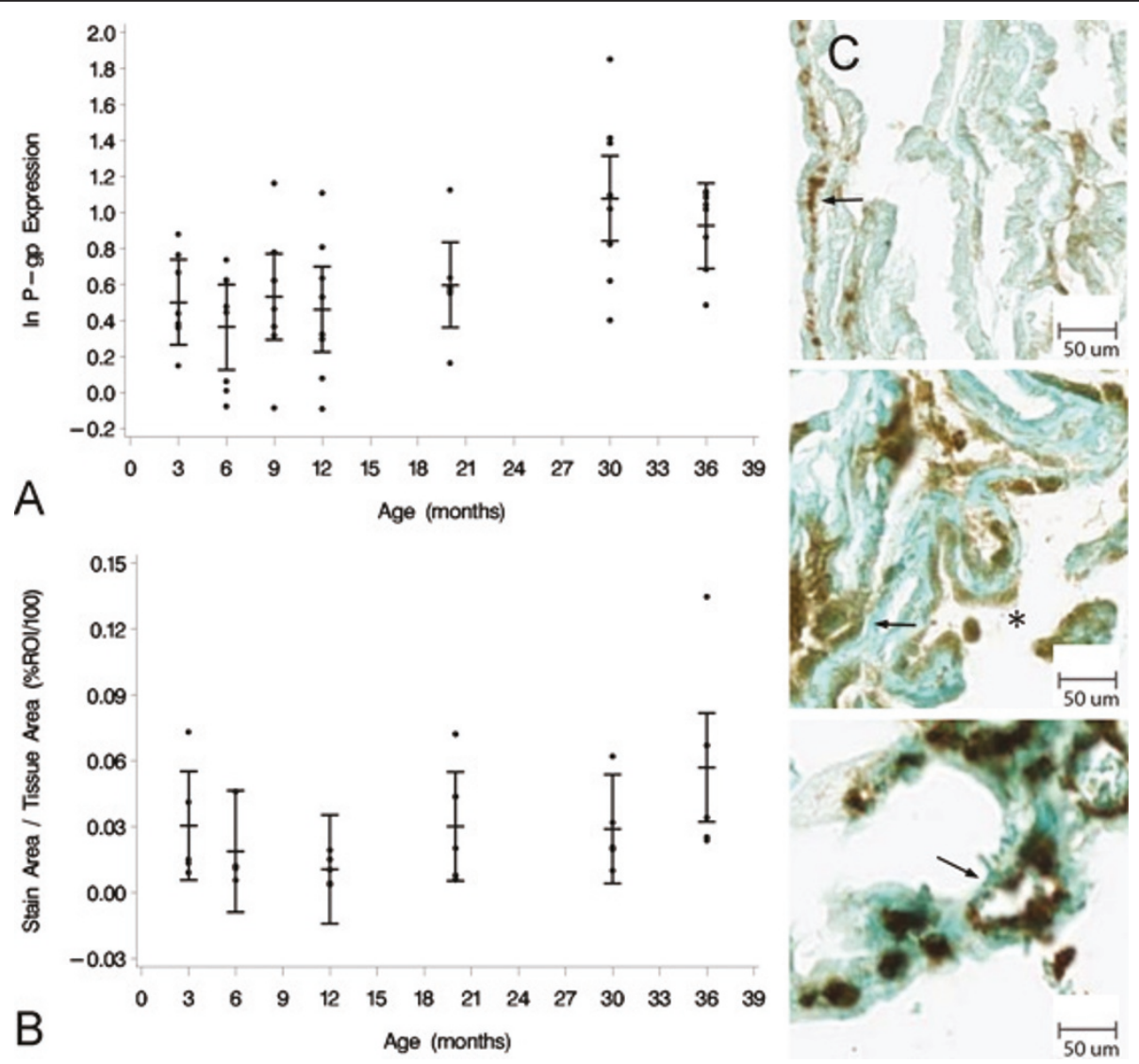

Figure 3 Age-related P-gp expression at the CP. (A) Graph of the log-transformed normalized expression of P-gp with respect to age, $n=8$ for each age group. One-way ANOVA revealed a significant increase $(p=0.0005)$ with age on P-gp expression. Significance was reached between $30 \mathrm{mo}$ and 3, 6, 9, and $12 \mathrm{mo}$, and between $36 \mathrm{mo}$ and 6 mo. Error bars represent 95\% confidence intervals for the means. (B) Semiquantitative IHC for P-gp expression. Stain area to tissue area ratio was not significantly different $(p>0.05)$ for the six age groups, $n=5$ per age group. (C) IHC of P-gp expression at $3 \mathrm{mo}$ (top), $20 \mathrm{mo}$ (center), and $36 \mathrm{mo}$ (bottom) old rats. Majority of staining is localized to the basolateral membrane (arrows), though on occasion it is seen along the apical membrane (asterisk).

expression in the $\mathrm{CP}$ epithelium increases with age at the mRNA level. This effect becomes significant at 30 mo. It should be noted that the increase at 36 mo was only significant when compared to the 6 mo age group.

Due to the punctate nature of the P-gp IHC staining, semi-quantitative image analysis of the IHC for the expression of P-gp (Figure 3B) compared the ratio of stained tissue area (pixels) to total tissue area (pixels) rather than mean stain intensity. No significant difference in this ratio was found for the different age groups at the $p<0.05$ level, though there was a general trend towards increased expression with age. P-gp staining was mainly localized to the basolateral $\mathrm{CP}$ epithelial membrane, though it was occasionally seen at the apical membrane as well (Figure 3C).

\section{RAGE}

The expression of RAGE with respect to age was also measured by RT-PCR. One-way ANOVA assessed the effect of age on the mean natural log-transformed normalized expression of RAGE at 3, 6, 9, 12, 20, 30 and 36 mo. There was no significant effect of age on the expression of RAGE at the $p<0.05$ level $[\mathrm{F}(6,49)=$ $0.88, p=0.52]$. Image analysis for the IHC performed for the RAGE protein confirmed that no significant differences between any of the age groups were present ( $p$ $=0.4041$ ). RAGE staining did not appear to localize to $\mathrm{CP}$ membranes but rather was cytosolic (PCR and IHC data not shown).

\section{$A \beta 40 / 42$}

IHC for $A \beta 40$ and $A \beta 42$ deposition was also analyzed semi-quantitatively. The mean staining intensity was not significantly different at the $p<0.05$ level for A $340, p=0.3384$, (data not shown), but there was a significant decrease with age $[\mathrm{F}(5,23)=6.40, p=$ 0.0007] for $A \beta 42$ (Figure 4A). Tukey's pairwise comparison showed a significant decrease in mean staining 


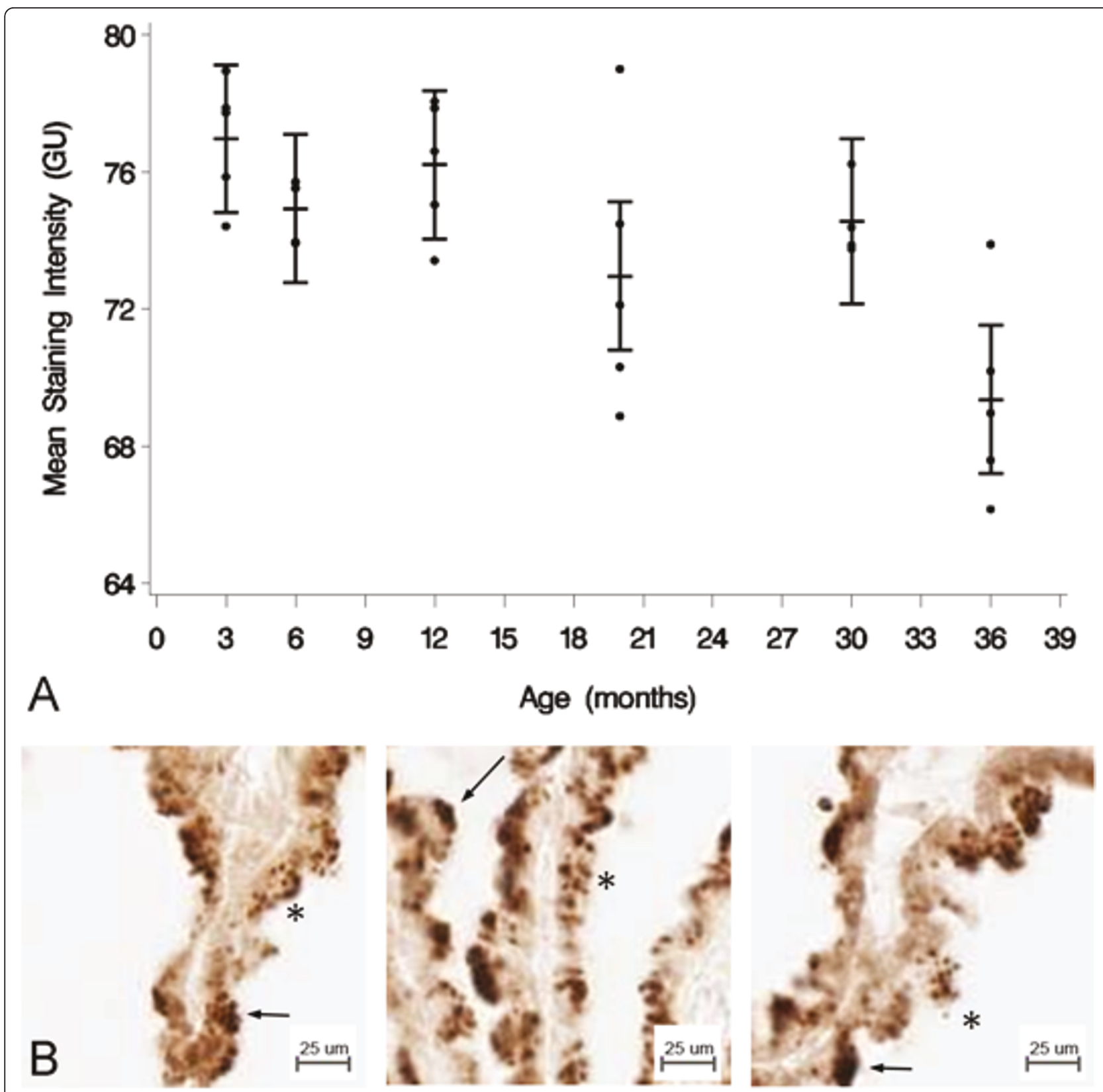

Figure $4 \mathrm{~A} \beta 42$ concentration in the CP epithelium with age. (A) Semi-quantitative $I H C$ for $A \beta 42$ deposition. Mean staining intensity in grayscale units (GU) was significantly decreased $(p<0.05)$ for the age groups, $n=5$ per age group. (B) IHC of A 42 at 3 mo (left), 20 mo (center), and $36 \mathrm{mo}$ (right) old rats. Staining is granular and primarily cytosolic (asterisks), though also found along the apical membrane (arrows).

intensity for $\mathrm{A} \beta 42$ between 3 and 36 mo [DBM = $-7.606 ; 95 \%$ CL $(-12.337,-2.874)], 6$ and 36 mo [DBM $=-5.567 ; 95 \%$ CL $(-10.299,-0.835)], 12$ and 36 mo $[\mathrm{DBM}=-6.839 ; 95 \% \mathrm{CL}(11.570,-2.170)]$, and 30 and 36 mo $[\mathrm{DBM}=-5.200 ; 95 \%$ CL $(-10.219,-0.812)]$. Age decreases $A \beta 42$ deposition in the $C P$ epithelium of the $\mathrm{B}-\mathrm{N} / \mathrm{F}$ rat. $\mathrm{A} \beta 42$ staining is granular and primarily cytosolic, though it was also found along the apical CP membrane (Figure 4B).
Figure 5 summarizes the $\mathrm{CP} A \beta$ transporters, as we believe they function from the data presented. The figure compares qualitatively the direction and expression of the transporters at three months (A) and after 20 months (B).

\section{Discussion}

Increased amyloid burden in the $\mathrm{AD}$ brain is neurotoxic and leads to neuritic plaque formation, chronic 

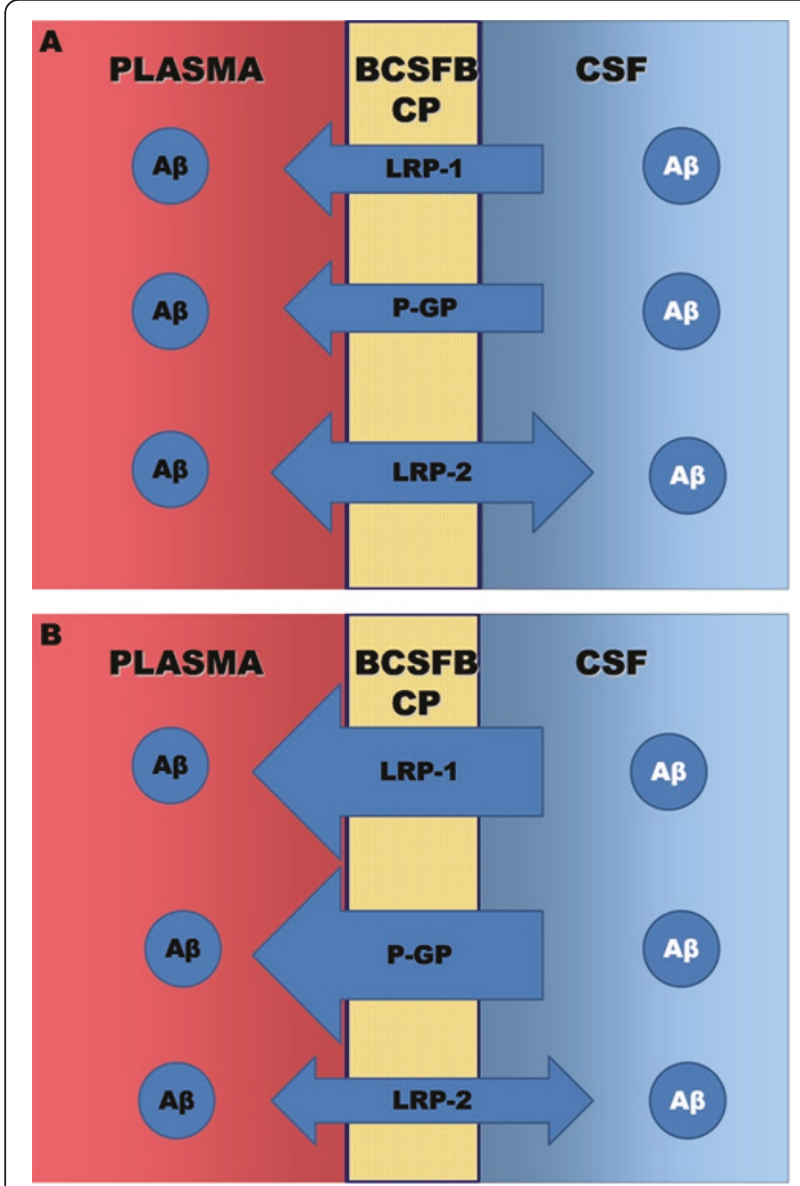

Figure 5 Diagrams of the direction and expression of the $A \beta$ transporters at the BCSFB. (A) Diagram to show the direction and relative expression of LRP-1, P-gp and LRP-2 at three months of age in the $B N / F$ rat. (B) Diagram of the relative expression of the three transporters after 20 months. Note that LRP-1 and P-gp expression increase, whereas LRP-2 expression decreases with age.

inflammation and neuronal death [2,31]. Amyloid accumulation is related to a decrease in $A \beta$ clearance $[4,7,8,20]$. It has been postulated that the lack of clearance from the brain via transporters at the BBB is the major mechanism behind $A \beta$ buildup in senescence and in $\mathrm{AD}[5,9,14,16]$. We now show that $\mathrm{A} \beta$ clearance at the BCSFB may be enhanced with age, reciprocal to $A \beta$ transporter alterations at the $\mathrm{BBB}$.

As noted, most $A \beta$ clearance pathways become compromised in the aged brain. Aside from the alterations in $\mathrm{BBB}$ transporter expression, and the attenuation of CSF bulk flow, enzymatic degradation of $A \beta$ by insulindegrading enzyme and/or neprilysin may also be diminished [32]. The CP epithelial cell surface area is enlarged by the basal labyrinth interdigitations and the apical microvilli, but is still less than the BBB endothelium. However, the contribution to $A \beta$ clearance by the $C P$ is not insubstantial, owing in part to the high levels of $A \beta$ degrading enzymes present [33]. Indeed, with the clearance deficits that occur at the $\mathrm{BBB}$, and the decrease in CSF turnover that occurs with age, the role of $A \beta$ transport and degradation at the BCSFB becomes increasingly more prominent. Between nine and 12 months of age in the $\mathrm{B}-\mathrm{N} / \mathrm{F}$ rat aging model, whole brain $\mathrm{A} \beta$ rises rapidly [5]. At 12 months of age $\mathrm{CP} A \beta 42$ begins to decrease as P-gp expression starts to increase and LRP-2 expression is decreasing. LRP-1 expression remains stable until 20 months and then increases.

Central to the functioning of the BCSFB is the $\mathrm{CP}$, the organ responsible for monitoring both plasma and CSF concentrations of many solutes, e.g., vitamins, hormones, harmful metabolites and immune cells, and regulating solute concentrations $[26,34,35]$. The CP likely influences neurogenesis in the damaged brain through the CSF transport of mitogenic growth factors to neurogenic niches near the ventricular wall [36]. In aging and in $\mathrm{AD}$ there is a decrease in the production and turnover of CSF allowing toxic metabolites, such as $A \beta$, more retention time in the brain $[7,21,23]$. At the same time there is a flattening of the $\mathrm{CP}$ epithelium, thickening of the basement membrane, and overall atrophy of the CP cells $[37,38]$. Therefore, it is of major interest that, despite these dystrophic $\mathrm{CP}$ changes, our aging rat $\mathrm{CP}$ data shows an increase in expression of the $\mathrm{A} \beta$ efflux transporters LRP-1 and P-gp, and either no change (RAGE) or a decrease in the expression of the CP influx transporter (LRP-2) in association with a significant decrease in CP A $\beta 42$ concentration, as measured by IHC. This observation may have a significant bearing on the transition that occurs between normal aging and $\mathrm{AD}$.

$\mathrm{A} \beta$ concentration is increased in the $\mathrm{CP}$ of $\mathrm{AD}$ brains, and the expression of the $C P A \beta$ transporters is altered to decrease $A \beta$ efflux and/or degradation $[39,40]$. $A \beta$ is shuttled bi-directionally across the BCSFB, and the net flux and rate of $A \beta$ transport is determined by the combined expression and activities of the $\mathrm{CP} A \beta$ transporters [41]. The amount of data available at present for the cell membrane localization of the amyloid transporters, and the direction and activity of transport is small. Hence much more work needs to be done in these areas. However, the $A \beta$ efflux transporter expression increase and the decrease in $C P A \beta 42$ suggest a net increase in $\mathrm{A} \beta$ efflux at the $\mathrm{BCSFB}$ in the aging rat. Loss of this $A \beta$ clearance route may be a determining factor in the increase in $C P A \beta$ seen in $A D$. $A \beta$ accumulation in the $C P$ increases apoptosis and interferes with oxidative phosphorylation, disrupting the BCSFB and likely further decreasing CSF turnover [40]. $A \beta$ therefore contributes progressively to an inability to clear itself.

The low density lipoprotein receptor (LDLR) family is an ancient and highly conserved family of receptors 
with endocytic and cell signaling functions. These receptors bind a wide range of ligands, including $A \beta[42,43]$, and LRP-1 has been linked to AD $[18,44,45]$. LRP-1 has been localized to neurons, glial cells, the endothelial cells of the BBB and the epithelial cells of the BCSFB. It has been shown to bind both $A \beta 40$ and $A \beta 42$, alone, or conjugated to one of their carrier proteins, and remove them from the extracellular space. Once bound, LRP-1 can target $\mathrm{A} \beta$ for cellular degradation, or facilitate its transcytosis [46]. A fully functional soluble form, sLRP1 , can also be found in the plasma, brain ISF and CSF [47]. At the BBB, LRP-1 transports $A \beta$ out of the brain. BBB LRP-1 expression has been shown to decrease significantly in aging and in $\mathrm{AD}[9,10]$. At the BCSFB, LRP-1 actively transports A $\beta$ out of the CSF [27].

The present study demonstrates that the mRNA expression and protein levels of LRP-1 increase in CP, and an increase in SLRP-1 in the CSF with advancing age has been reported [47]. It has been shown that A $\beta 42$ can increase the CSF shedding of membranebound LRP-1 as sLRP-1 [47]. An increase of sLRP-1 would create an $A \beta$ sink in the CSF, allowing $A \beta$ to accumulate in the CSF by binding to sLRP-1. When bound, $A \beta$ would be inhibited from self-aggregation. The bound $A \beta$ would be transferred to the systemic circulation for degradation.

LRP-2 is another member of the LDLR family known to transport $A \beta$ at the BCSFB. LRP-2 is expressed on capillary endothelium and $\mathrm{CP}$ epithelium, though its expression is 17-fold higher in CP epithelium [48]. It has been demonstrated that LRP-2 binds to $A \beta 40$ when it is conjugated to apolipoprotein J (ApoJ) and transports it into the CP epithelial cell from the CSF [29]. LRP-2 also transports solutes from blood into the CP epithelium, and from there into the CSF and brain. LRP-2 has not only been implicated in A $\beta$ transport, but also the transport of leptin and insulin-like growth factor 1 (IGF-1) from the peripheral circulation, across the $\mathrm{CP}$, and into the brain $[49,50]$. Transport of $\mathrm{A} \beta$ into the $\mathrm{CP}$ cells may keep it from forming aggregates within the cell, or it could facilitate its degradation by endolysosomes. At the BBB, LRP-2 acts in a manner similar to RAGE, transporting $A \beta$ out of the blood and into brain. However its high saturability with ApoJ not bound to $A \beta$ may restrict its role in $A \beta$ influx transport at the BBB [51]. LRP-2 actions at the BCSFB are less clear. It appears to transport solutes into the CP epithelium from both blood and CSF, and either degrades them within the cell or transports certain ones into the brain via the CSF. The present study finds the transcription of LRP-2 in CP to be significantly down-regulated with age, and its protein levels also decreased. Other groups have shown a similar decrease in the protein levels of LRP-2 at the BCSFB with age and AD $[39,49,50]$. The decline of LRP-2 expression with age might restrict the passage of $A \beta$ into the $C P$ epithelium; however, this could also restrict certain neuroprotectants like IGF-1 transported by LRP- 2 into the CSF and brain. It has been suggested that this lack of neuroprotectant transport leads to cognitive decline [49].

$\mathrm{P}$-gp is a member of the ATP binding cassette superfamily. This is another highly promiscuous receptor which exhibits a high degree of cross-reactivity with a number of unrelated substances. As an efflux transporter it acts to protect the brain at the BBB by pumping xenobiotics out of the brain $[28,52]$. It has been demonstrated that $\mathrm{P}$-gp is decreased at the $\mathrm{BBB}$ late in aging $[9,17]$. Its role at the BCSFB, however, is poorly understood. In this study, P-gp transcript expression significantly increased with advancing age. IHC localized P-gp primarily to the basolateral membrane of the epithelial cells, suggesting solute transport from the CP into the peripheral circulation. Other studies have not shown this basolateral localization of P-gp. Rao et al. (1999) concluded that P-gp was located sub-apically from staining patterns and functional tests [53]. Age seems to be the most likely explanation for this discrepancy between studies. In that study, neonatal CPs and cell cultures were used, rather than adult and aged rats as in the present study. It is possible that cell signaling directs P-gp to different membrane sites at various stages of life.

Another endocytic receptor and transporter of $A \beta$ is RAGE. It is a member of the immunoglobulin superfamily and its ligands include many diverse proteins which have undergone post-translational modifications [54]. As part of the innate immunity of the brain, the interaction between RAGE and its ligands can stimulate an inflammatory response and lead to oxidative stress within cells [55]. RAGE-A $\beta$ interaction at the $\mathrm{BBB}$ has also been shown to lead to $\mathrm{T}$-cell infiltration of the brain [56]. At the $\mathrm{BBB}, \mathrm{RAGE}$ expression increases with advancing age and $A D$, increasing $A \beta$ influx $[5,12]$. Few studies have explored the role of RAGE at the BCSFB. One study showed that RAGE increases in the CP after diabetic ketoacidosis, interestingly, without an increase in amyloid [30]. Both the transcript expression and the protein analysis in our study did not show any significant change with increased age, nor did the IHC demonstrate clearly the sub-cellular location of RAGE. It is unclear at this point what the role of RAGE is at the BCSFB in relation to $A \beta$ transport.

Our data show that the $A \beta$ efflux transporter up-regulation at the BCSFB occurs in a manner opposite to that in the $\mathrm{BBB}$, suggesting a possible compensatory role for the $\mathrm{CP}$ in eliminating amyloid from the CSF, CP and brain in aging. Although more confirmatory studies need to be done to be certain of the localization and direction of transport of the LRP receptors on the CP, it 
is important to note that $\mathrm{A} \beta 42$ was shown to significantly decrease in the $\mathrm{CP}$ with increased age as one would predict from the transporter expressions and directions that we have reported. This differs from the findings in the CPs of AD patients [39,40]. Other studies have also found differences between aging and $\mathrm{AD}$ in the CSF levels of sLRPs [47] and transthyretin, known to bind $A \beta$ in the CSF and impede amyloid fibrillogenesis [57]. Both of these proteins are decreased in AD compared to age-matched controls. The changes in $A \beta$ transporter expression at the BBB between aging and $\mathrm{AD}$ are in the same direction, though more severe in $\mathrm{AD}$. The differences between aging and $\mathrm{AD}$ at the $\mathrm{CP}$ and BCSFB may be where the normal aging brain and AD brain differ the most. These differences, and the signaling mechanisms behind them, may provide some insight into the complex relationship between aging and AD.

\section{Conclusions}

Aging alters the expression of the amyloid transporter genes at the BCSFB in a way that may facilitate amyloid clearance across the $\mathrm{CP}$ epithelium, i.e., there is an increase in the expression of the $A \beta$ efflux transporters LRP-1 and P-gp, whereas the CP A $\beta$ influx transporter LRP-2 is decreased. The changes in expression of the $A \beta$ transporter genes at the BCSFB are opposite to those seen at the $\mathrm{BBB}$ in aging, and may be a compensatory mechanism to aid the failing $\mathrm{BBB} A \beta$ clearance pathways. Eventual failure of this compensatory mechanism may have implications for $A \beta$ accumulation in both normal aging and in AD.

\section{Competing interest disclosures}

There are no actual or potential competing interests (conflicts of interest) to disclose for any of the authors or their families.

\footnotetext{
Abbreviations

$A \beta$ : amyloid-beta peptide; $A \beta 40: 40$ amino acid $A \beta ; A \beta 42$ : 42 amino acid $A \beta$; AD: Alzheimer's disease; ANOVA: analysis of variance; BBB: blood-brain barrier; BCSFB: blood-CSF barrier; B-N/F: Brown-Norway/Fischer (rat); cDNA: complementary deoxyribonucleic acid; CL: confidence limits; CP: choroid plexus; CSF: cerebrospinal fluid; GU: grayscale units; HRP: horseradish peroxidase; IHC: immunohistochemistry; LRP-1: low density lipoprotein receptor-related protein-1; LRP-2: low density lipoprotein receptor-related protein-2 (megalin); mRNA: messenger ribonucleic acid; PBS: phosphatebuffered saline; PFA: paraformaldehyde; P-gp: P-glycoprotein; RAGE: receptor for advanced glycation end-products; RT-PCR: real time (quantitative) polymerase chain reaction; SLRP-1: soluble LRP-1; TBST: Tris-buffered saline with Tween-20.
}

\section{Acknowledgements}

Special thanks to Elizabeth Kenney and Virginia Hovanesian for technical contributions.

Funding: Funding for this project was provided by the $\mathrm{NIH}$ grant: $1 \mathrm{RO} 1$ AG027910-01A1 and the Saunders Family Fund at the Neurosurgery Foundation, Brown University and Rhode Island Hospital.

\section{Author details}

${ }^{1}$ Warren Alpert Medical School Brown University, RI Hospital Department of Neurosurgery 593 Eddy St. Providence, RI 02903 USA. ${ }^{2}$ University of Rhode Island Department of Computer Science and Statistics Kingston, RI 02881 USA.

\section{Authors' contributions}

$C P$ and CC did the real time RT-PCR measurements and CP wrote the first draft of the manuscript. MCM and MB did the immunostaining and edited the manuscript, LG did the statistical analysis, and GDS conceived the research plan, organized the results and edited the manuscript. INC and CEJ reviewed the results and edited and corrected the manuscript. All authors have read and approved the final version of the manuscript.

Received: 17 March 2011 Accepted: 8 July 2011 Published: 8 July 2011

\section{References}

1. Hardy J: A hundred years of Alzheimer's disease research. Neuron 2006, 52:3-13.

2. Querfurth HW, LaFerla FM: Alzheimer's disease. N Eng J Med 2010, 362:329-344.

3. Yankner BA, LU T: Amyloid beta-protein toxicity and the pathogenesis of Alzheimer disease. J Biol Chem 2009, 284:4755-4759.

4. Selkoe DJ: Toward a comprehensive theory for Alzheimer's disease. Hypothesis: Alzheimer's disease is caused by the cerebral accumulation and cytotoxicity of amyloid beta-protein. Ann NY Acad Sci 2000, 924:17-25

5. Silverberg GD, Miller MC, Messier AA, Majmudar S, Machan JT, Donahue JE, Stopa EG, Johanson CE: Amyloid deposition and influx transporter expression at the blood-brain barrier increase in normal aging. $J$ Neuropathol Exp Neurol 2010, 69:98-108.

6. Yankner BA, Lu T, Loerch P: The aging brain. Ann Rev Pathol 2008, 3:41-66.

7. Rubenstein E: Relationship of senescence of cerebrospinal fluid circulatory system to dementias of the aged. Lancet 1998, 351:283-285.

8. Mawuenyega KG, Sigurdson W, Ovod V, Munselli T, Kasten T, Morris JC, Yarasheski KE, Bateman RJ: Decreased Clearance of CNS $\beta$-Amyloid in Alzheimer's Disease. Science 2010, 330:1774

9. Silverberg GD, Messier AA, Miller MC, Machan JT, Majmudar S, Stopa EG, Donahue JE, Johanson CE: Amyloid efflux transporter expression at the blood-brain barrier declines in normal aging. J Neuropathol Exp Neurol 2010, 69:1034-1043.

10. Donahue JE, Flaherty SL, Johanson CE, Duncan JA, Silverberg GD, Miller MC, Tavares R, Yang W, Wu Q, Sabo E, Hovanesian V, Stopa EG: RAGE, LRP-1, and amyloid-beta protein in Alzheimer's disease. Acta Neuropathol (Berl) 2006, 11:405-415.

11. Deane R, Zlokovic BV: Role of the blood-brain barrier in the pathogenesis of Alzheimer's disease. Curr Alzheimer Res 2007, 4:191-197.

12. Miller MC, Tavares R, Johanson CE, Hovanesian V, Donahue JE, Gonzalez L, Silverberg GD, Stopa EG: Hippocampal RAGE immunoreactivity in early and advanced Alzheimer's disease. Brain Res 2008, 1230:273-280.

13. Preston JE: Ageing choroid plexus-cerebrospinal fluid system. Microsc Res Tech 2001, 52:31-37.

14. Silverberg GD, Mayo M, Saul T, Rubenstein E, McGuire D: Alzheimer's disease, normal-pressure hydrocephalus, and senescent changes in CSF circulatory physiology: a hypothesis. Lancet Neurol 2003, 2:506-511.

15. Tanzi RE, Moir RD, Wagner SL: Clearance of Alzheimer's Abeta peptide: the many roads to perdition. Neuron 2004, 43:605-608.

16. Zlokovic BV: Clearing amyloid through the blood-brain barrier. Neurochem 2004, 89:807-811.

17. Hartz AM, Miller DS, Bauer B: Restoring blood-brain barrier P-glycoprotein reduces brain $A\{$ beta\} in a mouse model of Alzheimer's disease. $\mathrm{Mol}$ Pharmacol 2010, 77:715-723.

18. Shibata M, Yamada S, Kumar SR, Calero M, Bading J, Frangione B, Holtzman DM, Miller CA, Strickland DK, Ghiso J, Zlokovic BV: Clearance of Alzheimer's amyloid-ss(1-40) peptide from brain by LDL receptorrelated protein-1 at the blood-brain barrier. J Clin Invest 2000, 106:1489-1499.

19. Deane R, Du Yan S, Submamaryan RK, LaRue B, Jovanovic S, Hogg E, Welch D, Manness L, Lin C, Yu J, Zhu H, Ghiso J, Frangione B, Stern A, Schmidt AM, Armstrong DL, Arnold B, Liliensiek B, Nawroth P, Hofman F, Kindy $M$, Stern D, Zlokovic B: RAGE mediates amyloid-beta peptide 
transport across the blood-brain barrier and accumulation in brain. Nat Med 2003, 9:907-913.

20. Lu T, Pan Y, Kao S, Li C, Kohane I, Chan J, Yankner BA: Gene regulation and DNA damage in the ageing human brain. Nature 2004, 429:883-891.

21. May C, Kaye JA, Atack JR, Schapiro MB, Friedland RP, Rapoport SI: Cerebrospinal fluid production is reduced in healthy aging. Neurology 1990, 40:500-503.

22. Silverberg GD, Miller MC, Machan JT, Johanson CE, Caralopoulos IN, Pascale CL, Heile A, Klinge PM: Amyloid and Tau accumulate in the brains of aged hydrocephalic rats. Brain Res 2010, 1317:286-296.

23. Silverberg GD, Heit G, Huhn S, Jaffe RA, Chang SD, Bronte-Stewart $H$, Rubenstein E, Possin K, Saul TA: The cerebrospinal fluid production rate is reduced in dementia of the Alzheimer's type. Neurology 2001, 57:1763-1766.

24. Silverberg GD, Huhn $S$, Jaffe RA, Chang SD, Saul T, Heit G, Von Essen A, Rubenstein E: Downregulation of cerebrospinal fluid production in patients with chronic hydrocephalus. J Neurosurg 2002, 97:1271-1275.

25. Johanson CE, Duncan JA, Stopa EG, Baird A: Enhanced prospects for drug delivery and brain targeting by the choroid plexus-CSF route. Pharmaceut Res 2005, 22:1011-1037.

26. Spector $\mathrm{R}$, Johanson CE: Vectorial ligand transport through mammalian choroid plexus. Pharm Res 2010, 27:2054-2062.

27. Behl M, Zhang Y, Monnot AD, Jiang W, Zheng W: Increased beta-amyloid levels in the choroid plexus following lead exposure and the involvement of low-density lipoprotein receptor protein-1. Toxicol Appl Pharmacol 2009, 240:245-254.

28. de Lange $E C$ : Potential role of $A B C$ transporters as a detoxification system at the blood-CSF barrier. Adv Drug Deliv Rev 2004, 56:1793-1809.

29. Hammad SM, Ranganathan S, Loukinova E, Twal WO, Argraves WS: Interaction of apolipoprotein J-amyloid beta-peptide complex with low density lipoprotein receptor-related protein-2/megalin. A mechanism to prevent pathological accumulation of amyloid beta-peptide. J Biol Chem 1997, 272:18644-18649

30. Hoffman WH, Artlett CM, Zhang W, Kreipke CW, Passmore GG, Rafols JA, Sima AA: Receptor for advanced glycation end products and neuronal deficit in the fatal brain edema of diabetic ketoacidosis. Brain Res 2008, 1238:154-162.

31. Haass C, Selkoe DJ: Soluble protein oligomers in neurodegeneration: lessons from the Alzheimer's amyloid $\beta$-peptide. Nat Rev Mol Cell Biol 2007, 8:101-112

32. Caccamo A, Oddo S, Sugarman MC, Akbari Y, LaFerla FM: Age- and regiondependent alterations in Abeta-degrading enzymes: implications for Abeta-induced disorders. Neurobiol Aging 2005, 26:645-654.

33. Crossgrove JS, Smith EL, Zheng W: Macromolecules involved in production and metabolism of beta-amyloid at the brain barriers. Brain Res 2007, 1138:187-195.

34. Emerich DF, Skinner SJM, Borlongan CV, Vasconcellos AV, Thanos CG: The choroid plexus in the rise, fall and repair of the brain. Bioessays 2005, 27:262-274.

35. Smith DE, Johanson CE, Keep RF: Peptide and peptide analog transport systems at the blood-CSF barrier. Adv Drug Deliv Rev 2004, 56:1765-1791.

36. Johanson C, Stopa E, Baird A, Sharma H: Traumatic brain injury and recovery mechanisms: Peptide modulation of periventricular neurogenic regions by the choroid plexus-CSF nexus. I Neural Transm 2011, 118:115-133.

37. Serot J, Béné M, Faure GC: Choroid plexus, aging of the brain, and Alzheimer's disease. Front Biosci 2003, 8(suppl):5515-521.

38. Johanson C, McMillan P, Tavares R, Spangenberger A, Duncan J, Silverberg G, Stopa E: Homeostatic capabilities of the choroid plexus epithelium in Alzheimer's disease. Cerebrospinal Fluid Res 2004, 1:3.

39. Alvira-Botero X, Carro EM: Clearance of amyloid-peptide across the choroid plexus in Alzheimer's disease. Curr Aging SC 2010, 3:219-229.

40. Vargas T, Ugalde C, Spuch C, Antequera D, Morán MJ, Martín MA, Ferrer I, Bermejo-Pareja F, Carro E: Abeta accumulation in choroid plexus is associated with mitochondrial-induced apoptosis. Neurobiol Aging 2008, 31:1569-1581

41. Segal MB: The choroid plexuses and the barriers between the blood and the cerebrospinal fluid. Cell Mol Neurobiol 2000, 20:183-196.

42. Herz J, Bock HH: Lipoprotein receptors in the nervous system. Annu Rev Biochem 2002, 71:405-434.
43. Lillis AP, Van Duyn LB, Murphy-Ullrich JE, Strickland DK: LDL receptorrelated protein 1: unique tissue-specific functions revealed by selective gene knockout studies. Physiol Rev 2008, 88:887-918.

44. Harris-White ME, Frautschy SA: Low density lipoprotein receptor-related proteins (LRPs), Alzheimer's and cognition. Curr Drug Targets CNS Neurol Disord 2005, 4:469-480

45. Kang DE, Pietrzik CU, Baum L, Chevallier N, Merriam DE, Kounnas MZ, Wagner SL, Troncosco JC, Kawas CH, Katzman R, Koo EH: Modulation of amyloid beta-protein clearance and Alzheimer's disease susceptibility by the LDL receptor-related protein pathway. J Clin Invest 2000, 106:1159-1166.

46. Jaeger S, Pietrzik CU: Functional role of lipoprotein receptors in Alzheimer's disease. Curr Alzheimer Res 2008, 5:15-25.

47. Liu Q, Zhang J, Tran H, Verbeek MM, Reiss K, Estus S, Bu G: LRP1 shedding in human brain: roles of ADAM10 and ADAM17. Mol Neurodegener 2009, 4:17.

48. Chun JT, Wang L, Pasinetti GM, Finch CE, Zlokovic BV: Glycoprotein 330/ megalin (LRP-2) has low prevalence as mRNA and protein in brain microvessels and choroid plexus. Exp Neurol 1999, 157:194-201.

49. Carro E, Spuch C, Trejo JL, Antequera D, Torres-Aleman I: Choroid plexus megalin is involved in neuroprotection by serum insulin-like growth factor I. J Neurosci 2005, 25:10884-10893.

50. Dietrich MO, Spuch C, Antequera D, Rodal I, de Yébenes JG, Molina JA, Bermejo F, Carro E: Megalin mediates the transport of leptin across the blood-CSF barrier. Neurobiol Aging 2008, 29:902-912.

51. Zlokovic BV, Martel CL, Matsubara E, McComb JG, Zheng G, McCluskey RT, Frangione B, Ghiso J: Glycoprotein 330/megalin: probable role in receptor-mediated transport of apolipoprotein $\mathrm{J}$ alone and in a complex with Alzheimer disease amyloid beta at the blood-brain and bloodcerebrospinal fluid barriers. Proc Natl Acad Sci USA 1996, 93:4229-4234.

52. Sharom FJ: Shedding light on drug transport: structure and function of the P-glycoprotein multidrug transporter (ABCB1). Biochem Cell Biol 2006, 84:979-992.

53. Rao W, Dahlheimer JL, Bardgett ME, Snyder AZ, Finch RA, Sartorelli AC, Piwnica-Worms D: Choroid plexus epithelial expression of MDR1 P glycoprotein and multidrug resistance-associated protein contribute to the blood-cerebrospinal-fluid drug-permeability barrier. Proc Nat Acad Sci USA 1999, 96:3900-3905.

54. Srikanth V, Maczurek A, Phan T, Steele M, Westcott B, Juskiw D, Münch G: Advanced glycation endproducts and their receptor RAGE in Alzheimer's disease. Neurobiol Aging 2011, 32:763-777.

55. Chen X, Walker DG, Schmidt AM, Arancio O, Lue L, Yan SD: RAGE: a potential target for Abeta-mediated cellular perturbation in Alzheimer's disease. Curr Mol Med 2007, 7:735-742.

56. Li M, Shang D, Zhao W, Tian L, Li B, Fang W, Zhu L, Man SM, Chen YH: Amyloid beta interaction with receptor for advanced glycation end products up-regulates brain endothelial CCR5 expression and promotes T cells crossing the blood-brain barrier. J Immunol 2009, 182:5778-5788.

57. Serot J, Christmann D, Dubost T, Couturier M: Cerebrospinal fluid transthyretin: aging and late onset Alzheimer's disease. J Neurol Neurosurg Psychiatry 1997, 63:506-508.

doi:10.1186/2045-8118-8-21

Cite this article as: Pascale et al: Amyloid-beta transporter expression at the blood-CSF barrier is age-dependent. Fluids and Barriers of the CNS 2011 8:21. 